\title{
Forthcoming in Language Teaching
}

\section{State-of-the-Art Articles}

Shulin Yu \& Icy Lee on Peer feedback in second language writing (2005-2014)

\section{A Country in Focus}

Rhonda Oliver, Honglin Ghen \& Stephen Moore on Selected research in applied linguistics published in Australia (2008-2014)

\section{Replication Studies}

Fiona Willans \& Constant Leung on Empirical foundations for medium of instruction policies: Approximate replications of Afolayan (1976) and Siegel (1997)

\section{Plenary Speeches $^{1}$}

John Flowerdew on Corpus-based approaches to language description for specialized academic writing

Lynda Yates on Learning how to speak: Pronunciation, pragmatics and practicalities in the classroom and beyond

\section{First Person Singular}

\section{Susan Gass}

\section{Thinking Allowed}

Ema Ushioda on Language learning motivation through a small lens: A research agenda

\footnotetext{
${ }^{1}$ Plenary speeches currently available online ahead of print publication can be read in First View Articles, via journals.cambridge.org/lta
} 